\title{
Pulmonary Function and Effects of Body Position in Patients with Obstructive Sleep Apnea
}

\author{
Sei Won Kim, Hyeon Hui Kang, Woo Ho Ban, and Sang Haak Lee \\ Division of Pulmonary, Critical Care and Sleep Medicine, Department of Internal Medicine, Eunpyeong St. Mary's Hospital, \\ College of Medicine, The Catholic University of Korea, Seoul, Korea
}

\begin{abstract}
Objective: Obstructive sleep apnea (OSA) is known to be associated with upper airway collapse during sleep. However, OSA has also been suggested to have effects on the lower airway. This study examined the association between pulmonary function test (PFT) results during daytime and OSA according to the severity of OSA and presence of obesity. Changes in PFT results with body position (sitting vs. supine) were also analyzed. Methods: A total of 46 patients who were diagnosed with OSA were included in this study. Patients were grouped according to the severity of OSA and presence of obesity. Results: Obese, severe OSA patients tended to show poorer pulmonary function than non-obese, mild-to-moderate OSA patients. Forced expiratory volume in 1 second/forced vital capacity (FEV $1 / F V C$; sitting), peak expiratory flow (PEF; sitting), and forced expiratory flow during the middle half of the $\mathrm{FVC}\left(\mathrm{FEF}_{25-75}\right.$; supine) were significantly lower in the severe OSA group than the mild-to-moderate OSA group ( $p=0.020, p=0.044$, and $p=0.042$, respectively). Positional change from sitting to the supine position significantly reduced pulmonary function in the total OSA patient population. The effect of body position on PFT results was greater in non-obese, mild-to-moderate OSA patients. $\mathrm{FEF}_{25-75}$ in the sitting position was still significantly related to the apnea-hypopnea index in OSA patients after adjusting for other factors $(p=0.048)$. Conclusion: This study indicated that relationships exist between lower airway function, body position, and OSA. The PFT is a simple test that can provide useful information about the upper and lower airways in OSA patients.
\end{abstract}

Key Words: Pulmonary function test; Body position; Spirometry; Obstructive sleep apnea; Obesity

Received: November 6, 2019 Revised: December 9, 2019 Accepted: December 10, 2019

Corresponding author: Sang Haak Lee, MD, PhD, Division of Pulmonary, Critical Care and Sleep Medicine, Department of Internal Medicine, Eunpyeong St. Mary's Hospital, College of Medicine, The Catholic University of Korea, 1021 Tongil-ro, Eunpyeong-gu, Seoul 03312, Korea.

Tel: 82-2-2030-4640, Fax: 82-2-2030-4641, E-mail: mdlee@catholic.ac.kr

(a) This is an Open Access article distributed under the terms of the Creative Commons Attribution Non-Commercial License (https://creativecommons.org/licenses/bync/4.0) which permits unrestricted non-commercial use, distribution, and reproduction in any medium, provided the original work is properly cited.

\section{INTRODUCTION}

Obstructive sleep apnea (OSA) is characterized by repetitive upper airway narrowing or collapse during sleep, which induces frequent arousal and oxygen desaturation [1,2]. OSA affects about $3.2-4.5 \%$ of the population of Korea and is associated with significant morbidity and mortality [3].

Polysomnography (PSG) is essential for diagnosis of OSA. However, PSG is expensive and requires specialized facilities and a significant amount of time to complete. Therefore, there have been attempts to develop other simple methods for diagnosing OSA, and to identify useful markers of the condition [4]. The negative expiratory pressure test, which consists of applying negative pressure during early expiration, has been suggested as one such method $[4,5]$. In addition, there have also been attempts to apply the results of the pulmonary function test (PFT) to the diagnosis and treatment of OSA [6-9].

The PFT is frequently performed in hospitals, and produces standardized results that are easy for clinicians to interpret. The PFT can also provide information on the lower respiratory tract, which may be involved in the pathogenesis of upper airway disease. Other studies also suggested that there are associations between OSA and intrathoracic airways [10-12].

In addition, there have been several reports regarding the effects of body position and obesity on PFT results $[7,13,14]$. In healthy subjects, PFT results are generally better in the sitting position than the supine position [15-17]. The sitting position was also reported to improve pharyngeal airway collapsibility in patients with OSA compared with the supine position [18]. However, there have been few studies focusing on the relation- 
ship between OSA and PFT results in both the sitting and supine positions; moreover, none of the existing studies are recent and they enrolled only small numbers of patients $[7,8]$.

The present study was performed to examine the association between PFT results and OSA according to the severity of OSA and presence of obesity. Changes in PFT results with body position (sitting to supine) were also analyzed. We hypothesized that changes in PFT results with body position may be a useful indicator of OSA, especially in non-obese, non-severe OSA patients.

\section{METHODS}

\section{Subjects}

A total of 46 patients at Eunpyeong St. Mary's Hospital, who were diagnosed with OSA using type 1 PSG, were included in this study. PSG was performed in the sleep laboratory of Eunpyeong St. Mary's Hospital. Diagnosis and measurement of the severity of OSA were performed according to the definition of the American Academy of Sleep Medicine [1]. The inclusion criteria were 1) patients with OSA over 18 years of age and 2) patients who are able to undergo PFT in both the sitting and supine positions. The exclusion criteria were 1) pulmonary or infectious diseases; 2) any other medical condition that could affect pulmonary function; and 3) difficulties in sitting or lying in the supine position. Approval was obtained from the Institutional Review Board of Eunpyeong St. Mary's Hospital (PC18EESI0060). All patients provided written informed consent prior to enrolment in the study.

\section{Clinical measurements}

Demographic data, including sex, age, body mass index (BMI), and smoking history were collected. Comorbidities, including diabetes, hypertension, congestive heart failure and cerebrovascular accidents, were also recorded. Apnea-hypopnea index (AHI), nadir peripheral capillary oxygen saturation $\left(\mathrm{SpO}_{2}\right)$, oxygen desaturation index (ODI), and respiratory disturbance index (RDI) were determined based on the results of PSG.

\section{Pulmonary function test in the sitting and supine positions}

The PFTs were performed using a SensorMedics Vmax 229 instrument (Viasys Healthcare, Yorba Linda, CA, USA) during daytime. Before the PFT, each patient inhaled a short-acting bronchodilator (beta-2 agonist; salbutamol) four times within a period of 30 seconds. Although there is a low probability of air flow limitation reversibility in patients with normal spirometry [19], we nevertheless attempted to remove this confounding factor. The PFT was performed in the sitting position first, and then repeated 10 minutes later in the supine position.

\section{Data analysis and statistics}

Changes in PFT results with body position (sitting to supine) were analyzed in the total population. For subgroup analysis, the subjects were divided according to the severity of OSA and the presence of obesity. The mild-to-moderate OSA group ( $5 \leq \mathrm{AHI}$ $<30$ ) was compared with the severe OSA group (AHI $\geq 30)$. Obesity was defined as BMI $\geq 30 \mathrm{~kg} / \mathrm{m}^{2}$. The mean and standard deviation were computed for normally distributed continuous variables, whereas the median and interquartile range (IQR, 25th to 75th percentile) were calculated for non-normally distributed continuous data. Categorical data are presented as numbers (\%). The paired t-test was used to compare PFT results between the sitting and supine positions in the same patients. Student's t-test was performed for normally distributed data, and the Mann-Whitney Utest for non-normally distributed data, to compare clinical data between subgroups. Categorical variables were compared using the chi-square and Fisher's exact tests, as appropriate. Missing values were excluded from the analyses. Simple and multiple linear regression analyses were performed to identify the independent clinical predictors of AHI. Clinical parameters with a p-value $<0.2$ on simple regression analysis were included in multiple linear regression analysis. Statistical analyses were performed using R software (ver. 3.5.3; R Development Core Team, R Foundation for Statistical Computing, Vienna, Austria). In all analyses, $\mathrm{p}<0.05$ was taken to indicate statistical significance.

\section{RESULTS}

\section{Basic patient characteristics}

Table 1 lists the basic characteristics of the patients. Of the 46 patients with OSA, $82.6 \%$ were male. The mean age and BMI were $55.8 \pm 15.1$ years and $30.0 \pm 6.1 \mathrm{~kg} / \mathrm{m}^{2}$, respectively. The percentages of never-smokers, ex-smokers, and current smokers were $39.1 \%$, $47.8 \%$, and $13.0 \%$, respectively. Hypertension was the most common comorbidity in the total study population (58.7\%), followed by diabetes (32.6\%), cerebrovascular accidents (4.3\%), and congestive heart failure (2.2\%). The PSG results revealed mean AHI, mean ODI, and median RDI values of 43.8 $\pm 24.8,37.4 \pm 23.6$, and 37.4 (IQR: 30.5-67.9), respectively. The mean nadir $\mathrm{SpO}_{2}$ was 80.0 (IQR: 74.0-86.0).

We also performed subgroup analysis according to the severity of OSA and presence of obesity. Comparison of the mild-to-moderate OSA group with the severe OSA group indicated no significant differences in basic characteristics, except for parameters related to OSA ( $\mathrm{p}<0.001$ for $\mathrm{AHI}$, nadir $\mathrm{SpO}_{2}, \mathrm{ODI}$, and RDI). There were no significant differences between groups according to the presence of obesity, except for BMI $(\mathrm{p}<0.001)$.

\section{Pulmonary function in the sitting and supine positions}

Among all OSA patients, there were significant differences in PFT results between the sitting and supine positions (Figure 1A). Compared with the sitting position, forced vital capacity (FVC, $\%)$, forced expiratory volume in 1 second $\left(\mathrm{FEV}_{1}, \%\right), \mathrm{FEV}_{1} / \mathrm{FVC}$ (\%), forced expiratory flow during the middle half of the FVC $\left(\mathrm{FEF}_{25-75}, \%\right)$, and peak expiratory flow (PEF, \%) were all significantly lower in the supine position ( $\mathrm{p}<0.001$ for all comparisons). 
Table 1. Basic patient characteristics

\begin{tabular}{|c|c|c|c|c|c|c|c|}
\hline & \multicolumn{3}{|c|}{ OSA } & \multicolumn{3}{|c|}{ Obesity } & \multirow{2}{*}{ Total } \\
\hline & Mild-to-moderate OSA & Severe OSA & $\mathrm{p}$-value & No $(\mathrm{BMI}<30)$ & Yes $(B M I \geq 30)$ & $\mathrm{p}$-value & \\
\hline Number of patients & 10 & 36 & & 24 & 22 & & 46 \\
\hline Male sex & $7(70.0)$ & $31(86.1)$ & 0.473 & $22(91.7)$ & $16(72.7)$ & 0.192 & $38(82.6)$ \\
\hline Age (yr) & $54.4 \pm 19.4$ & $56.2 \pm 13.9$ & 0.735 & $57.9 \pm 16.2$ & $53.6 \pm 13.7$ & 0.346 & $55.8 \pm 15.1$ \\
\hline BMI $\left(\mathrm{kg} / \mathrm{m}^{2}\right)$ & $28.8 \pm 6.4$ & $30.4 \pm 6.1$ & 0.487 & $25.6 \pm 3.1$ & $34.9 \pm 4.8$ & $<0.001$ & $30.0 \pm 6.1$ \\
\hline Smoking & & & 0.307 & & & 0.171 & \\
\hline Never-smoker & $6(60.0)$ & $12(33.3)$ & & $10(41.7)$ & $8(36.4)$ & & $18(39.1)$ \\
\hline Ex-smoker & $3(30.0)$ & $19(52.8)$ & & $13(54.2)$ & $9(40.9)$ & & $22(47.8)$ \\
\hline Current-smoker & $1(10.0)$ & $5(13.9)$ & & $1(4.2)$ & $5(22.7)$ & & $6(13.0)$ \\
\hline PYRS & $0.0[0.0-8.5]$ & $13.2[0.0-24.5]$ & 0.192 & $6.3[0.0-31.0]$ & $10.8[0.0-20.0]$ & 0.708 & $8.1[0.0-24.0]$ \\
\hline $\mathrm{DM}$ & $3(30.0)$ & $12(33.3)$ & 1.000 & $8(33.3)$ & $7(31.8)$ & 1.000 & $15(32.6)$ \\
\hline $\mathrm{HBP}$ & $5(50.0)$ & $22(61.1)$ & 0.788 & $15(62.5)$ & $12(54.5)$ & 0.804 & $27(58.7)$ \\
\hline $\mathrm{CHF}$ & $0(0.0)$ & $1(2.8)$ & 1.000 & $1(4.2)$ & $0(0.0)$ & 1.000 & $1(2.2)$ \\
\hline CVA & $0(0.0)$ & $2(5.6)$ & 1.000 & $1(4.2)$ & $1(4.5)$ & 1.000 & $2(4.3)$ \\
\hline AHI & $11.2[8.0-14.2]$ & $45.3[34.0-72.5]$ & $<0.001$ & $39.7 \pm 23.0$ & $48.2 \pm 26.5$ & 0.250 & $43.8 \pm 24.8$ \\
\hline Nadir $\mathrm{SpO}_{2}(\%)$ & 88.0 [87.0-91.0] & $78.5[72.0-83.0]$ & $<0.001$ & $80.0[73.5-86.0]$ & $80.0[75.0-87.0]$ & 1.000 & $80.0[74.0-86.0]$ \\
\hline ODI & $6.4 \pm 3.6$ & $46.5 \pm 18.6$ & $<0.001$ & $33.9 \pm 23.7$ & $41.1 \pm 23.5$ & 0.319 & $37.4 \pm 23.6$ \\
\hline RDI & $12.6[10.4-16.8]$ & $41.7[34.2-74.3]$ & $<0.001$ & 34.6 [28.9-46.5] & $41.2[33.6-70.7]$ & 0.359 & 37.4 [30.5-67.9] \\
\hline
\end{tabular}

Data are presented as $\mathrm{n}(\%)$, mean \pm SD, or median [interquartile range]. OSA: obstructive sleep apnea, BMI: body mass index, PYRS: pack years, DM: diabetes mellitus, HBP: high blood pressure, CHF: congestive heart failure, CVA: cerebrovascular accident, AHI: apnea-hypopnea index, $\mathrm{SpO}_{2}$ : peripheral capillary oxygen saturation, $\mathrm{ODI}$ : oxygen desaturation index, RDI: respiratory disturbance index

In subgroup analysis according to the severity of OSA, the mild-to-moderate and severe OSA groups both showed significantly lower values in all PFT parameters in the supine position compared with the sitting position (Table 2). In addition, the severe OSA group generally showed lower values for all PFT parameters regardless of body position compared with the mild-tomoderate OSA group. Among the parameters, $\mathrm{FEV}_{1} / \mathrm{FVC}$ in the sitting position, $\mathrm{PEF}$ in the sitting position, and $\mathrm{FEF}_{25-75}$ in the supine position were significantly lower in the severe OSA group compared with the mild-to-moderate OSA group $(\mathrm{P}=0.020$, $\mathrm{p}=0.044$, and $\mathrm{p}=0.042$, respectively).

Subgroup analysis based on the presence of obesity showed similar tendencies to subgroup analysis based on severity of OSA. The obesity and control groups both showed significantly lower values for all PFT parameters in the supine position compared with the sitting position. The obesity group tended to show lower values for the PFT parameters compared with the non-obese group. FEV and PEF in the sitting position were significantly different between the two groups ( $\mathrm{p}=0.049$ and $\mathrm{p}=0.030$, respectively).

\section{Degree of change in pulmonary function with change in}

body position according to the severity of OSA and obesity

The mild-to-moderate OSA group tended to show greater changes in pulmonary function parameters with change in body position compared with the severe OSA group (Figure 1B). However, the differences were not statistically significant.

The non-obese group showed greater changes in pulmonary function parameters with change in body position than the obese group (Figure 1C). The values of $\triangle \mathrm{FVC}(\%), \triangle \mathrm{FEV}_{1}(\%)$, and $\triangle \mathrm{FEF}_{25-75}(\%)$ showed significant differences between the two groups ( $\mathrm{p}=0.038, \mathrm{p}=0.008$, and $\mathrm{p}=0.007$, respectively).

\section{Clinical parameters associated with $\mathrm{AHI}$ in patients with OSA}

On multiple regression analysis, $\mathrm{FEF}_{25-75}$ in the sitting position showed a significant association with AHI $(\mathrm{p}=0.048)$ (Table 3 ). The degree of pulmonary function change was not significantly associated with AHI. BMI was also not directly related to AHI.

\section{DISCUSSION}

In this study, we analyzed the daytime PFT results of OSA patients to determine the associations between OSA, pulmonary function, and body position. In the total OSA patient population, a significant decrease in pulmonary function was seen with a change from the sitting to the supine position; the decrease remained significant in subgroup analysis according to severity of OSA and presence of obesity. In addition, obese, severe OSA patients tended to show poor pulmonary function, and little change therein with a change from the sitting to the supine position, compared with non-obese, mild-to-moderate OSA patients. Finally, $\mathrm{FEF}_{25-75}$ in the sitting position was still significantly related to AHI after adjusting for other factors.

OSA is known to be associated with an increased likelihood of complete or partial upper airway collapse during sleep. However, OSA has also been suggested to have effects on the intrathoracic airways [10-12]. As well as the anatomical aspects, lower airway inflammation and oxidative stress may also impact pulmonary 

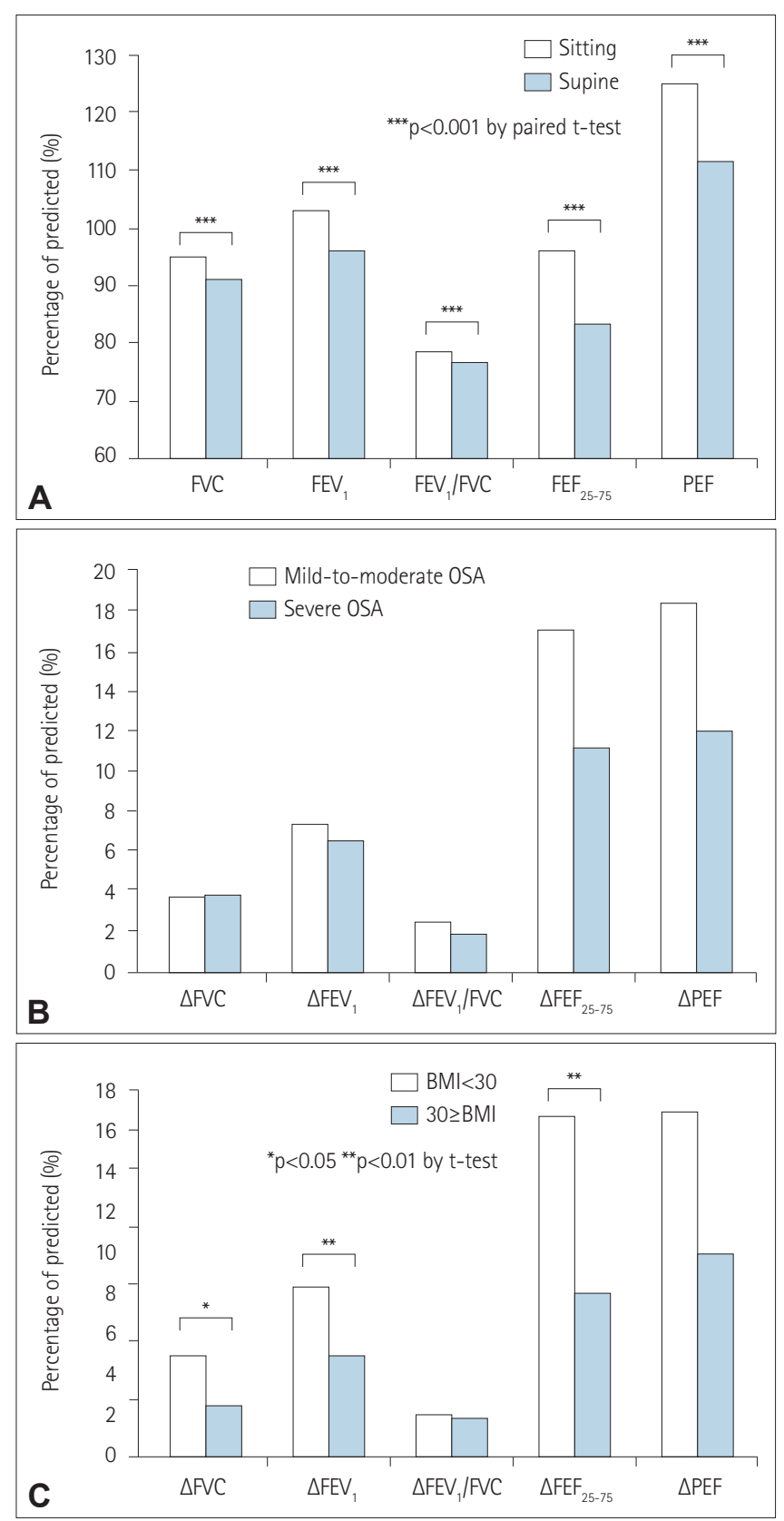

Figure 1. Change in pulmonary function test parameters in patients with OSA with change in body position (sitting vs. supine). (A) Pulmonary function in the sitting and supine positions. (B) Degree of pulmonary function change with change in body position in the mild-to-moderate OSA group and severe OSA group. (C) Degree of pulmonary function change with change in body position according to the presence of obesity. FVC: forced vital capacity, FEV1: forced expiratory volume in 1 second, $\mathrm{FEF}_{25-75}$ : forced expiratory flow during the middle half of the FVC, PEF: peak expiratory flow.

function [20]. Negative relationships were reported between the severity of OSA and PFT parameters, such as expiratory reserve volume [21], functional residual capacity [10], $\mathrm{FEV}_{1}[12,22]$, and FVC $[12,23]$. Although the absolute values of the PFT parameters in both of our groups were within the normal ranges, the severe OSA group tended to show poorer pulmonary function compared with the mild-to-moderate OSA group. Values of $\mathrm{FEV}_{1} /$ FVC in the sitting position, $\mathrm{PEF}$ in the sitting position, and $\mathrm{FEF}_{25}$ -
75 in the supine position were significantly different between the mild-to-moderate OSA and severe OSA groups. These results suggested the possibility of intrathoracic airflow disturbance in the severe OSA group compared with the mild-to-moderate OSA group. Reduction of pulmonary function according to the severity of OSA could be more meaningful in patients with respiratory disease, such as chronic obstructive pulmonary disease. The presence of OSA may exacerbate airway inflammation, and possibly lead to further deterioration of pulmonary function in patients with respiratory disease [24]. We also compared patients with OSA according to the presence of obesity, which is an important factor in OSA and respiratory function. Obese individuals are known to show reduced lung volume and capacity compared with individuals of normal weight [25]. The impact of obesity on lung function is multifactorial, encompassing both mechanical and inflammatory aspects [26]. Obese OSA patients tended to show poorer pulmonary function compared with non-obese OSA patients in the present study, which was consistent with a previous report [25]. There were no patients with obesity-hypoventilation syndrome $(\mathrm{OHS})$ in our study population. However, we could not exclude a diagnosis of OHS due to a lack of daytime $\mathrm{PaCO}_{2}$ results.

According to the American Thoracic Society/European Respiratory Society (ATS/ERS) guidelines, the PFT may be performed in either the sitting or standing position, and the position should be recorded on the report [27]. There have been several reports regarding the effects of body position on lung function in healthy populations, obese subjects, asthma patients, and patients with spinal cord injury [13]. Pulmonary function was generally reported to be better in the sitting position compared with the supine position, except in some studies of patients with spinal cord injury.

Sleep position is an important factor in OSA, and patients are more likely to experience apneic events in the supine position [28]. Lung function was significantly better in the sitting position compared with the supine position in the total OSA population in the present study. The decrease in lung volume from the sitting position to the supine position may facilitate upper airway and intrathoracic airway collapse or closure, due to loss of caudal traction tension, and contribute to increased resistance in the airways [29]. Interestingly, the effect of position on pulmonary function was more prominent in our non-obese, mild-to-moderate OSA group than the obese, severe OSA group. These results suggest that the effect of position on the intrathoracic airway is greater in non-obese, mild-to-moderate OSA patients. In addition, obese, severe OSA patients already have lower pulmonary function compared with other OSA patient subgroups, even in the sitting position.

The relationship between decreased pulmonary function and severity of OSA must be interpreted carefully, because BMI is a strong confounding factor for this association [12]. In this study, $\mathrm{FEF}_{25-75}$ in the sitting position was the only factor significantly associated with AHI on multiple regression analysis. Although there has been some controversy regarding the association be- 
Table 2. Pulmonary function in the sitting and supine positions

\begin{tabular}{|c|c|c|c|c|c|c|c|}
\hline & \multicolumn{3}{|c|}{ OSA } & \multicolumn{3}{|c|}{ Obesity } & \multirow{2}{*}{ Total } \\
\hline & Mild-to-moderate & Severe & p-value & No $(\mathrm{BMI}<30)$ & Yes $(\mathrm{BMI} \geq 30)$ & p-value & \\
\hline \multicolumn{8}{|l|}{ Sitting position } \\
\hline FVC (\%) & $96.2 \pm 18.6$ & $94.6 \pm 13.7$ & 0.761 & $98.6 \pm 13.7$ & $90.9 \pm 14.8$ & 0.074 & $94.9 \pm 14.6$ \\
\hline $\mathrm{FEV}_{1}(\%)$ & $108.6 \pm 15.9$ & $101.4 \pm 15.2$ & 0.197 & $107.2 \pm 14.4$ & $98.3 \pm 15.5$ & 0.049 & $103.0 \pm 15.4$ \\
\hline $\mathrm{FEV}_{1} / \mathrm{FVC}(\%)$ & $82.8 \pm 7.6$ & $77.5 \pm 5.7$ & 0.020 & $78.0 \pm 7.5$ & $79.4 \pm 5.0$ & 0.464 & $78.7 \pm 6.4$ \\
\hline $\mathrm{FEF}_{25-75}(\%)$ & $118.0 \pm 46.1$ & $89.6 \pm 28.4$ & 0.091 & $101.3 \pm 41.2$ & $89.7 \pm 24.8$ & 0.250 & $95.8 \pm 34.5$ \\
\hline $\operatorname{PEF}(\%)$ & $136.7 \pm 26.6$ & $122.2 \pm 17.3$ & 0.044 & $131.5 \pm 18.6$ & $118.6 \pm 20.2$ & 0.030 & $125.3 \pm 20.2$ \\
\hline \multicolumn{8}{|l|}{ Supine position } \\
\hline FVC (\%) & $92.5 \pm 17.9$ & $90.8 \pm 12.8$ & 0.733 & $93.6 \pm 13.7$ & $88.5 \pm 13.9$ & 0.211 & $91.2 \pm 13.9$ \\
\hline $\mathrm{FEV}_{1}(\%)$ & $101.2 \pm 15.7$ & $94.9 \pm 14.8$ & 0.247 & $99.0 \pm 14.5$ & $93.4 \pm 15.4$ & 0.211 & $96.3 \pm 15.0$ \\
\hline $\mathrm{FEV}_{1} / \mathrm{FVC}(\%)$ & $80.3 \pm 7.0$ & $75.7 \pm 6.5$ & 0.059 & $75.9 \pm 8.0$ & $77.5 \pm 5.4$ & 0.426 & $76.7 \pm 6.8$ \\
\hline $\mathrm{FEF}_{25-75}(\%)$ & $100.8 \pm 38.4$ & $78.4 \pm 27.5$ & 0.042 & $84.6 \pm 36.4$ & $81.7 \pm 24.9$ & 0.756 & $83.2 \pm 31.1$ \\
\hline $\operatorname{PEF}(\%)$ & $118.2 \pm 23.3$ & $110.1 \pm 17.1$ & 0.228 & $114.8 \pm 20.1$ & $108.7 \pm 16.9$ & 0.275 & $111.8 \pm 18.7$ \\
\hline
\end{tabular}

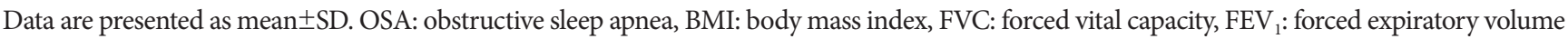
in 1 second, $\mathrm{FEF}_{25-75}$ : forced expiratory flow during the middle half of the FVC, PEF: peak expiratory flow

Table 3. Clinical parameters associated with apnea-hypopnea index in patients with obstructive sleep apnea

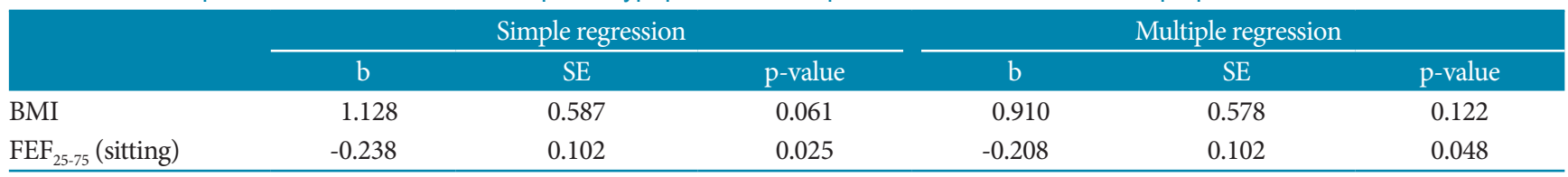

BMI, body mass index; $\mathrm{FEF}_{25-75}$, forced expiratory flow during the middle half of the FVC

tween pulmonary function and severity of OSA independent of obesity [23], our results were obtained after correction for BMI. Associations between lung volume and severity of OSA were also reported in studies matching subjects for BMI, or that adjusted for BMI $[21,22] . \mathrm{FEF}_{25-75}$ is considered an early marker of small airway disease [30]. The association between $\mathrm{FEF}_{25-75}$ and the value of AHI suggests the possibility of a relationship between OSA and lower airway pulmonary function. Several underlying mechanisms have been suggested, including airway inflammation and oxidative stress [20].

Our study had several limitations. First, the study population was small and a large proportion of patients were obese and had severe OSA. Therefore, we combined patients with mild or moderate OSA into one group. In addition, obesity was defined as BMI $\geq 30 \mathrm{~kg} / \mathrm{m}^{2}$. However, the non-obese group also showed a high mean BMI, of $25.6 \mathrm{~kg} / \mathrm{m}^{2}$. Second, we attempted to control for important confounding factors, and patients with pulmonary disease or any other disease that can affect lung function were excluded. Patients who could not perform the test for any reason, and who were suspected to have pulmonary diseases based on spirometry results, were also excluded. Therefore, there was a possibility of selection bias in our study. Third, the PFT parameters were measured in the daytime, and were therefore not reflective of airflow during sleep, which was the main parameter of interest. Finally, we only performed spirometry, without examining lung volume or the diffusion capacity of the lungs for carbon monoxide. This study was performed to assess the intrathoracic airflow using a simple test. However, there were limitations in terms of under- standing the lung mechanics in detail.

In conclusion, this study demonstrated the relationships of pulmonary function, body position, and OSA. Obese, severe OSA patients showed poorer pulmonary function, and also tended to show little change in PFT results with change in body position, compared with non-obese, mild-to-moderate OSA patients. $\mathrm{FEF}_{25-75}$ was correlated with AHI. Overall, the PFT can provide important information about upper and lower respiratory function in OSA patients. The PFT is easy to apply and may be useful as an early indicator of OSA.

\section{Acknowledgments}

This study was partly supported by Clinical Trials Center of Eunpyeong St. Mary's Hospital.

\section{Conflicts of Interest}

The authors have no potential conflicts of interest to disclose.

\section{Author Contributions}

Conceptualization: Sei Won Kim, Hyeon Hui Kang, Sang Haak Lee. Formal analysis: Sei Won Kim. Methodology: Sei Won Kim. Project administration: Sang Haak Lee. Resources: Sang Haak Lee. Writing_original draft: Sei Won Kim. Writing_review \& editing: Sei Won Kim, Hyeon Hui Kang, Woo Ho Ban, Sang Haak Lee.

\section{ORCID iDs}

Sang Haak Lee (D)

https://orcid.org/0000-0001-6259-7656 
Sei Won Kim (1)

https://orcid.org/0000-0002-2798-421X

\section{REFERENCES}

1. Sleep-related breathing disorders in adults: recommendations for syndrome definition and measurement techniques in clinical research. The Report of an American Academy of Sleep Medicine Task Force. Sleep 1999;22:667-689.

2. Eckert DJ, Malhotra A. Pathophysiology of adult obstructive sleep apnea. Proc Am Thorac Soc 2008;5:144-153.

3. Kim J, In K, Kim J, You S, Kang K, Shim J,et al. Prevalence of sleep-disordered breathing in middle-aged Korean men and women. Am J Respir Crit Care Med 2004;170:1108-1113.

4. Carrera HL, Marcus CL, McDonough JM, Oliva Morera JC, Huang J, Farre R, et al. Negative expiratory pressure technique: an awake test to measure upper airway collapsibility in adolescents. Sleep 2015;38:1783-1791.

5. Oliveira LV, Romano S, Hirata RP, Faria Júnior NS, Giannasi LC, Nacif SR, et al. Negative expiratory pressure test: a new, simple method to identify patients at risk for obstructive sleep apnea. J Bras Pneumol 2011;37:659-663.

6. Zeng B, Ng AT, Darendeliler MA, Petocz P, Cistulli PA. Use of flow-volume curves to predict oral appliance treatment outcome in obstructive sleep apnea. Am J Respir Crit Care Med 2007;175:726-730.

7. Shore ET, Millman RP. Abnormalities in the flow-volume loop in obstructive sleep apnoea sitting and supine. Thorax 1984;39:775-779.

8. Miura C, Hida W, Miki H, Kikuchi Y, Chonan T, Takishima T. Effects of posture on flow-volume curves during normocapnia and hypercapnia in patients with obstructive sleep apnoea. Thorax 1992;47:524-528.

9. Fastenberg JH, Fang CH, Patel VM, Lin J, Stupak HD. The use of handheld nasal spirometry to predict the presence of obstructive sleep apnea. Sleep Breath 2018;22:79-84.

10. Abdeyrim A, Li N, Shao L, Heizhati M, Wang Y, Yao X, et al. What can impulse oscillometry and pulmonary function testing tell us about obstructive sleep apnea: a case-control observational study? Sleep Breath 2016;20:61-68.

11. Onal E, Leech JA, Lopata M. Relationship between pulmonary function and sleep-induced respiratory abnormalities. Chest 1985;87:437-441.

12. Kunos L, Lazar Z, Martinovszky F, Tarnoki AD, Tarnoki DL, Kovacs D, et al. Overnight changes in lung function of obese patients with obstructive sleep apnoea. Lung 2017;195:127-133.

13. Katz S, Arish N, Rokach A, Zaltzman Y, Marcus EL. The effect of body position on pulmonary function: a systematic review. BMC Pulm Med 2018;18:159.

14. Sebbane M, El Kamel M, Millot A, Jung B, Lefebvre S, Rubenovitch J, et al. Effect of weight loss on postural changes in pulmonary function in obese subjects: a longitudinal study. Respir Care 2015;60:992-999.

15. Meysman M, Vincken W. Effect of body posture on spirometric values and upper airway obstruction indices derived from the flow-volume loop in young nonobese subjects. Chest 1998;114:1042-1047.

16. Vilke GM, Chan TC, Neuman T, Clausen JL. Spirometry in normal subjects in sitting, prone, and supine positions. Respir Care 2000;45:407-410.

17. Ceridon ML, Morris NR, Olson TP, Lalande S, Johnson BD. Effect of supine posture on airway blood flow and pulmonary function in stable heart failure. Respir Physiol Neurobiol 2011;178:269-274.

18. Tagaito Y, Isono S, Tanaka A, Ishikawa T, Nishino T. Sitting posture decreases collapsibility of the passive pharynx in anesthetized paralyzed patients with obstructive sleep apnea. Anesthesiology 2010;113:812-818.

19. Hegewald MJ, Townsend RG, Abbott JT, Crapo RO. Bronchodilator response in patients with normal baseline spirometry. Respir Care 2012;57: 1564-1570.

20. Bikov A, Hull JH, Kunos L. Exhaled breath analysis, a simple tool to study the pathophysiology of obstructive sleep apnoea. Sleep Med Rev 2016;27:1-8.

21. Oztürk L, Metin G, Cuhadaroğlu C, Utkusavaş A, Tutluoğlu B. FEF(25-75)/ FVC measurements and extrathoracic airway obstruction in obstructive sleep apnea patients. Sleep Breath 2005;9:33-38.

22. Zerah-Lancner F, Lofaso F, Coste A, Ricolfi F, Goldenberg F, Harf A. Pulmonary function in obese snorers with or without sleep apnea syndrome. Am J Respir Crit Care Med 1997;156(2 Pt 1):522-527.

23. Bikov A, Losonczy G, Kunos L. Role of lung volume and airway inflammation in obstructive sleep apnea. Respir Investig 2017;55:326-333.

24. O'Brien A, Whitman K. Lack of benefit of continuous positive airway pressure on lung function in patients with overlap syndrome. Lung 2005;183: 389-404.

25. Melo LC, Silva MA, Calles AC. Obesity and lung function: a systematic review. Einstein (Sao Paulo) 2014;12:120-125

26. Dixon AE, Peters U. The effect of obesity on lung function. Expert Rev Respir Med 2018;12:755-767.

27. Miller MR, Crapo R, Hankinson J, Brusasco V, Burgos F, Casaburi R, et al. General considerations for lung function testing. Eur Respir J 2005;26:153161.

28. Frank MH, Ravesloot MJ, van Maanen JP, Verhagen E, de Lange J, de Vries N. Positional OSA part 1: towards a clinical classification system for position-dependent obstructive sleep apnoea. Sleep Breath 2015;19:473-480.

29. Abdeyrim A, Tang L, Muhamat A, Abudeyrim K, Zhang Y, Li N, et al. Receiver operating characteristics of impulse oscillometry parameters for predicting obstructive sleep apnea in preobese and obese snorers. BMC Pulm Med 2016;16:125.

30. Carr TF, Altisheh R, Zitt M. Small airways disease and severe asthma. World Allergy Organ J 2017;10:20. 